\title{
Face Management, Common Ground and Intention in Nigerian Pidgin Health Talk
}

\author{
Alege Tosin Caroline \\ Department of English and Literary Studies, Kogi State University, Anyigba, Nigeria \\ Email address: \\ tosinalege@gmail.com \\ To cite this article: \\ Alege Tosin Caroline. Face Management, Common Ground and Intention in Nigerian Pidgin Health Talk. Communication and Linguistics \\ Studies. Vol. 4, No. 2, 2018, pp. 54-64. doi: 10.11648/j.cls.20180402.15
}

Received: June 14, 2018; Accepted: July 30, 2018; Published: August 24, 2018

\begin{abstract}
The cognitive and the interactional paradigm clash engendered the current study as it undertakes a reassessment of the cognitive and the socio-cultural paradigms to meaning explication through a re-examination of face management, common ground, and by extension, intention, in the success of the communicative venture. To accomplish this, it addresses itself to such objectives as: to establish the extent of the dependence of face management and overall success in communication on common ground of participants, it seeks to know whether communicative intention is ipsofacto or post facto (emergent), and whether implicature is derived conventionally or collaboratively rather than from inferences about speaker's intention. The analysis applied the operational schema of face, intention and common ground postulated in the work to empirical data of the Nigerian pidgin radio discourse 'The World of Herbs' of the Edo State Broadcasting Corporation, to evolve valid conclusion on aspects of the inquiry. The findings indicate that common ground (items of information existing in memory or the physical environment) served as an invaluable resource in discourse in aspects of the shared pidgin code, mutual knowledge of topical issue, and access to comprehension through lucidity of expression characteristic of the radio discourse. As regards communicative intention, the analysis indicates that it may be perceived as both a priori and post facto in datum, while intention is recovered via implicature as product of intentionality and conventionality. Intentions are mostly displayed or cojointly constructed (post facto), especially in cases of normative or moral accountability. Overall, implicature is demonstrated as not derived from inferences about speaker's intention but through projective and retroactive inferencing. This leads us to the conclusion that the derivation of implicature in interaction is a matter of intentionality and conventionality, while common ground remains an adjustable, co-constructed construct in communication subject to participants' assessment of the contextual factors involved.
\end{abstract}

Keywords: Cognitivism, Interactionalism, Face Management, Common Ground, Intention, Implicature, Inference

\section{Introduction}

Linguistic politeness has been delineated as a system of communicative strategies manifesting in distinct forms across cultures. As a universal property of communicative situation by virtue of which interlocutors speak or behave in socially/culturally acceptable manner [1], it is only expected that vagaries of its manifestation abound across cultural boundaries. In pragmatic circles however, traditional focus has centred on the recognition of speaker's communicative intention and its attendant recovery for success in communication - a stance that has been strongly contested by the cognitive postulate [2] which focuses on utterance interpretation from the point of view of hearer to the detriment of the social constraints exerting on utterance production and force.

As noted by Rundquist [3] and Thomas [4], conversational inference (and by extension, matters of relevance, politeness, etc) may not survive solely on a cognitive foundation but its combination with the language user's social and cultural background. Accounting for meaning therefore transcend linguistic knowledge of speakers or hearers alone, but involves an all inclusive, dynamic process between [sic] context, participants and utterance potentials [4].

Noting the cognitive and the interactional paradigm clash and admitting the inadequacies of their cognitive model in handling the emergent properties of social interaction, Brown and Levinson [5] posit that "work in interaction as a system 
thus remains a fundamental research priority and the area from which improved conceptualizations of politeness are most likely to emerge. Emergent properties refer to the dynamic dimension of meaning in an on-going interaction which comes into being not necessarily by a prior design of speaker or hearer in a given interactional exchange, but by reason of conversational development in the context of the discourse.

The co-constituting model advanced by Arundale [6] to plug the hole in the Gricean account of communicationpresupposed by the Brown and Levinson model advances a theoretical model that arises from "work in interaction as a system; and addresses emergence in interaction" (p.199). Incidentally aspects of intention, common ground and implicature have assumed different dimensions in recent times as meaning or implicature is construed as a matter of conventionality; Davis [7], as well as a collaborative and emergent construct of interlocutors rather than dependent on inferences about speaker's intentions [8].

It is therefore the intent of the present study to explore the conflux of the cognitive and the interactional dimensions to meaning negotiation through the attendant pragmatic features of common ground, face management and communicative intention. In doing this it seeks to answer such questions as

What evidence from datum demonstrates the interconnectivity and interdependence of face work and common ground in the success of communication among participants of the pidgin radio discourse?

What supporting evidence(s) from the discourse demonstrate communicative intention as ipso facto/displayed or post facto/emergent in the Nigerian pidgin talk exchanges?

What evidence(s) from datum establish implicature as derived conventionally or collaboratively rather than from inferences about speaker's intention?

\section{Literature Review}

Pragmatics, according to Leech and Short [9], investigates aspects of meaning which are not derived from the properties of words and construction but rather from the way utterances are used and how they are related to the context in which they are uttered. This entails the nexus of speech acts, cooperative principle, presupposition, MCBs, implicature, face management, and context as pragmatic inputs exerting influence on the encoding and decoding processes of interlocutors in discourse.

Austin [10] asserts that linguistic actions (acts) are performed through our use of language. Identifying act types of locutionary, illocutionary and perlocutionary dichotomies, the locutionary act involves the production of a meaningful sentence to the intent of a certain communicative function which is the illocutionary force (which reveals the intention of the speaker), the perlocutionary effect on the other hand, is the response intended by the speaker from the hearer by reason of the combination of the locutionary act and the illocutionary force. However, as observed by Austin and corroborated by Cooper [11] "the prelocutionary effects are not...due to the intrinsic nature of sentences"; i.e., one can bring about a perlocutionary act by some other means other than the spoken words, and perlocutionary effect may turn out as intended or not. However the success of speech act and essentially illocutionary acts is premised on felicity conditions.

For communicative interactions to succeed, it becomes expedient for interlocutors to cooperate. As proposed by Grice [12], the Cooperative Principle is the quasiinteractional agreement which speakers enter into as they perform speech acts. It is therefore expected and assumed that interlocutors observe the quantity (volume of information required), quality (validity) relation (relevance) and manner (clarity) maxims. Interlocutors by their utterances can therefore abide by or flout the maxims to generate implicature recoverable via inferences, for in the words of Bach and Harnish [13], linguistic communication is an "inferential process"where speech acts are performed with the intention that the hearer identifies the act being performed. They identified success in communication as premised on the recognition of S's illocutionary intention so that "the intended effectof an act of communication is not just any effect produced by means of the recognition of the intention to produce a certain effect; it is the recognition of that effect".

Consequently, the identification of speaker's communicative ends contingent on shared knowledge of interlocutors forms the hub of successful meaning transaction and negotiation in context. In the words of Bach and Harnish [13], "the inference made by the hearer and the inference he takes himself to be intended to make is based not just on what the speaker says but also on mutual contextual beliefs (MCBs)"; i.e. salient information from the context known to both speaker and hearer which regulate their presupposition and implicature drawn. MCBs evident in speaker's intentions and hearer's inference must be mutual for effective communication. They identified the linguistic presumption (LP) and the communicative presumption (CP) where LP represents the mutual belief in a linguistic community that whenever any member utters an element of that language, the hearer, who is also a member, knows the meaning of the elements, and the $\mathrm{CP}$ denotes the mutual belief that a speaker who performs a speech act actually has an intention which he wants the hearer to recognize [14].

Another cooperative essence of communication as observed by Brown and Levinson [15] is face management which entails the presentation, maintenance of "self worth" or identity in communicative interaction. Face may however be maintained or damaged in conversation by recourse to communicative strategies which orient to interlocutor's positive face (desire for acceptance and appreciation by others) or negative face (desire for autonomy and independence, freedom from imposition by others). Speakers are said to constantly assess and make choices in wording face threatening utterances in consideration of the triad intricate variables of Power differential between speaker and hearer, Distance and Rating of imposition. To this end, 
speakers choose to perform face threatening Act (FTA) without redressive action, or use positive politeness, negative politeness, perform the FTA using off-record politeness, or choose not to perform the FTA at all.

Arundale [16] argues that the Gricean account cannot explain how meaning and intention are proactively and retroactively influenced due to the sequential interdependence of utterances in interaction. As noted by Haugh [17], Arundale argues for the centrality of the reflexive attribution of meanings, and the holding accountable of speakers for those meanings. He sees intention in analysis as a discursive description of events seen to have "directionality" and "aboutness".

Adducing the face co-constituting theory as a remedy, Arundale postulates a dyad and dynamic dimension to communication; an interactional achievement of communication where interlocutors mutually constrain and reciprocally influence one another's formulating of interpretings through their adjacent utterances. Unlike the encoding/decoding model it upholds a "dyad" rather than the individual as the minimum irreducible unit of analysis for communication, thereby accounting for the emergent properties for a better account of politeness in communication. The face-co-constituting model consists of the interpreting and the producing aspects governed by the sequential interpreting principle and the recipient design principle respectively.

Haugh [17] in his effort to reconcile cognitivephilosophical and socio-cultural interactional perspectives on intention using the Levinson three layer levels of analysis in human interaction viz; the individual (or linguistic), interactional and socio-cultural systems, he argues that while the continued existence of multiple perspectives on the place of intention in pragmatics is no doubt a means of advancing the discipline, he however posits that it is ultimately only through discarding certain views and developing new alternatives that we may ultimately deepen our understanding of meaning, communication and interaction.

Arundale [18] observed that in order to eschew explanations of talk-in-interaction in terms either of cognitive states or macro social concepts, conversation analysts have provided a strong socially-based explanation of talk-ininteraction, which reveals how the micro-social phenomena of conversation arise as individuals place utterances adjacent to those of other individuals.

It is the opinion of the current research that the empirical data analysed in this study will provide additional insight into the nature of intention and meaning recovery in practical contexts through interlocutors sequential ordering of utterances in interaction.

It may be observed that Neo-Grecian pragmatics locates the recognition of intention and subsequent recovery via the inferential procedure at the centre of the communicative enterprise. Whereas semantic minimalism and the sociocultural - interactional paradigms anchor success in communication on propositional semantic contents and emergent co-constructed meaning, but as observed by
Assimak- Opoulous [19] in reference tothe minimalist notion, semantic meaning represents a sort of "common core of meaning shared by every utterance of it" irrespective of contextual variables, with its point of departure from semanticminimalism being the simultaneous contextual development alongside its decoding for the attainment of full propositional status.

The semantic minimalists and the Neo-Gricean nexus is succinctly captured by Bilmes [20] submission that speaker's intentions are displayed (so far as they are displayed) because the utterance has meaning and therefore, the meaning of the utterance cannot be wholly based on speaker's displayed intention.

It therefore behooves interlocutors to fix the puzzle of linguistic under determinacy as a feature of the relation between linguistic expressions and the ideas they convey as many implicatures are rather derived from conventionality on generic constrains of contextually-shared understanding rather than hearer's recognition of speaker's intention Davis [7].

Shared understanding, common knowledge or common ground (hereafter CG) refers to mutual beliefs, suppositions which interlocutors bring to discourse encounters and on the basis of which they add their assertion in communication. Clark [21] asserts that interlocutors assess and reassess their CG in conversational activities on the basis of communal membership and personal experience. While communal CG refers to information common to a community of people on the basis of their joint experience (linguistic, communicative, perceptual) personal CG on the other handis shared linguistic and perceptual experience shared by two people which forms the basis for the accumulation of $C G$ in face-to-face conversational exchange..

Contemporary scholarship have however extended the scope of CG beyond its traditional conceptualization as a static mental property shared by interlocutors as cognitive psychology, linguistic pragmatics and inter-cultural communication have established $\mathrm{CG}$ as an emergent property of ordinary memory processes, Bar \&Keysar [22], Colston [23]; negotiated and constructed dynamically in communicative interaction. This conceptualization provides a basis to account for properties and realities of everyday communicative encounters such as disagreement and egocentrism of speaker(s) and hearer(s). The fallacy of shared "common core" meaning of lexical items has been found to differ in accordance with the circumstances of its encoding with a concomitant effect on subsequent recall and 'sameness' of meaning shared with fellow interlocutors as common ground. Relevance theorists, in consonance with Fodor [24] posit that the semantic content of a lexical item is inherited by the "real" semantics of its associated mental concept [2] which encompasses the encyclopedic entry (individual denotations and assumption schemas) resulting in varied semantic contents across individuals and negating the notion of 'common core meaning' shared by every usage of a lexical item in abstraction from individual contexts of use (Horsey cited by Assimakopoulos [19].) 
A closely related and interesting phenomenon is the egocentric tendency exhibited to a greater or lesser degree by individuals in language interactions. This tendency has been adduced by Bar and Keysar [22] as a principal underlying decisive factor in the initial and final stages of production and comprehension process of interlocutors.

Levels and strategies of egocentrism appear contingent upon the talk type and diverse motivational factors influencing interlocutors at any point in time. Discourse types necessitated by information transfer (instructional), negotiations, resolutions and persuasions appear to underscore a recourse to common ground as shared knowledge and emergent, interactively negotiated meaning than activity types in the categories of Drift, Avoidance, Reluctance, Emotional expressions, 'Freudian' and other slips, Responding in kind, Plagiarism, Mimicry, Attitude expression, Filibuster, Lubrication, Display, Getting it down, Mere continuance and Alignment among others; Colston [25], which are largely negligent ofaudience design and might not necessitate common ground monitoring for their production. The relativity of common ground to audience categories appears an intriguing dimension to what may be considered 'common ground' and its attendant pursuit in a communicative enterprise. This is so because factors of homogeneity (similarity) or heterogeneity (diversity) in audience composition and inclination may polarize or graduate common ground along a cline from a point of sameness to that of neutrality or even antagonism.

The complexities observed and their relative influences on the success or otherwise of the communicative enterprise compels a reassessment of common ground in terms of relevance and adjustment for different tasks and by different interlocutors. This essentiality become more compelling in that while 'deviant' forms mentioned above have comic effects on most occasions, others in the categories of Drift and re-anchor, Chase, Verbal play, Off loading, Good enough comprehension, Resource allocation, Intentionality and Common ground violation, Culture and common ground, Inevitability of egocentrism, and Failure to ground are confirmed mechanisms and variables enabling communication between interlocutors in the absence of common ground. It therefore behooves the progressive outlook to accommodate such avant-garde views as Colston's who submits that:

Common ground might thus be viewed as an adjustable Component of conversations, both in terms of how much it is needed for a task at hand, as well as how much different speakers wish to rely on it for a given conversational exchange [25].

Colston's submission above triggers Kecskes and Mey's [26] germane verdict on contemporary contentions on the status of common ground in interaction, viz; that common ground must comprise of both a priori and post factum elements where self regard dominates in certain phases of the communicative process where a priori elements are prioritized than in other phases of the same communicative process. Common ground is considered significant for the success of the pidgin health talk interactions in aspects of conceptualization of face and its concomitant management as well as the ultimate negotiation of meaning in discourse.

The review in this section covering aspects of speech acts, the cooperative principle, face, politeness, $\mathrm{MCBs}$, relevance, the face co-constituting theory, intention, common ground and implicature revealed that the postulates are interrelated and interdependent in communicative interaction. It may be observed that activity type and goal most often select the vagaries of relationships they exhibit in discourse. The interconnection between face, common ground, activity type and meaning negotiation is of paramount interest to the present study. Thus the research's conception of their relatedness is schematically represented in fig. 1 below. (Note: Babawarun is researcher's maiden name)

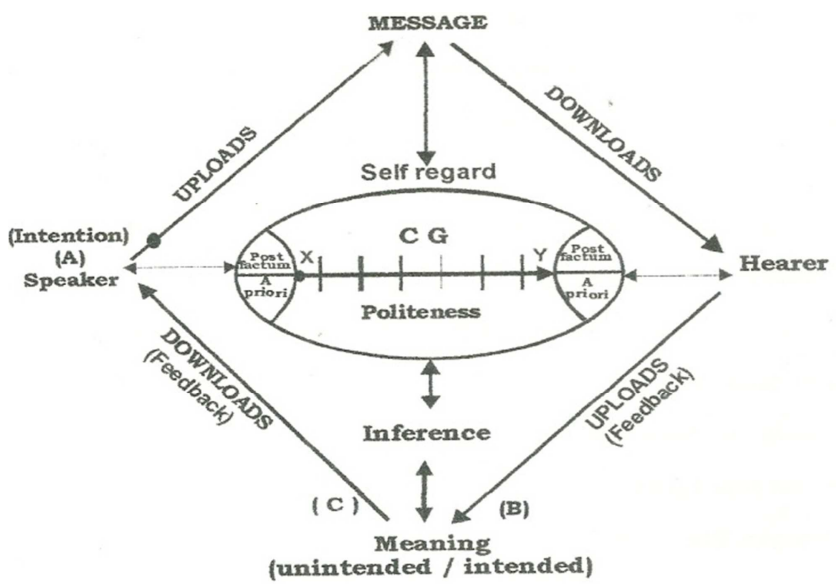

Figure 1. Babawarum's [27] Operational Schema of Face, Common Ground and Intention.

The schema locates common ground as being central to the success of communication, comprising of a priori and post factum components. Common ground (hereafter CG), subsuming presupposition and mutual knowledge, including mutual conceptualization of face; is represented as graduated along a continuum of a minimal point $\mathrm{X}$ (zero or least elaborated) to a maximum of $\mathrm{Y}$ (infinitum or richly elaborated).

The calibrations show $\mathrm{CG}$ as a dynamic, adjustable and emergent property of ordinary memory process;Bar\&Keysar [22], Colston [23], underpinned or regulated by the self regard of speaker and hearer in language use. Self regard of speaker/hearer regulates what is perceived, claimed and employed as CG which is in turn uploaded as input into the communicative process in congruency with the task in hand and the immediate and ultimate goal(s) of interlocutors. In other words, self regard (esteem, personality, public self image, interest, individualism, etc.) affects expectations for self and other in context as well as how, and the extent to which CG is used depending on interlocutors' perception of task/discourse domain (e.g. interrogation, debate, lecture, negotiation etc.) and the immediate and ultimate goal in view. Face and common ground are integrating within the context of discourse in that normative and strategic politeness derive their felicity from shared socio-cultural norms (CG) to 
which participants can relate. The shared knowledge, belief, conceptualization of face of participants equips them for the identification and interpretation of politeness strategies to the end of recovery of communicative intention and inferences in discourse. Conversely, CG (belief, knowledge, agreement, etc.) constitutes a veritable tool to the end of self and other face management. Hence, face management strategies are instrumental to the achievement of $\mathrm{CG}$, and $\mathrm{CG}$ functions as a face management tool.

The schema shows the initiation of the communicative process by speaker at point A. On the basis of his/her communicative intention, speaker draws on CG in uploading the message, an input which the hearer accesses and downloads through $\mathrm{CG}$ to arrive at intended or unintended meaning by inference. Hearer's upload task is characterized by indeterminacy as this depends, to a large extent, on the task in hand; i.e. hearer's input to CG is determined by the form of conversation or task in which interlocutors are engaged (e.g. lecture, debate, interrogation, etc.).

The downloaded CG is connected to meaning explication in full cognizance of anthological ambiguities; Haugh [17], i.e. what Speaker intends to imply is not necessarily what hearer comes to understand which explains why communication fails. Meaning (intended/ unintended) is shown as basic (hence located at the base) to the communicative venture based on the negotiated and dynamic paradigms of CG. Intended meaning is however placed at the right extreme of the inference arrow because intention is originally oblique to the hearer and only evolves over time through negotiation of $\mathrm{CG}$ (approximation to $\mathrm{Y}$ ). Nevertheless, context and the level of precision (deploying mutually perceivable $\mathrm{CG}$ ) often clearly spell out meaning and intention. Unintended meaning is, on the other hand, localised to the left $(\mathrm{X})$ extreme because utterances basically have meaning (conventional) and hearer makes recourse to what can or cannot be implied in that context except otherwise specified through the enrichment of common ground.

The success of an adjacency pair (a unit of talk) culminating in recovery of speaker's intended meaning is shown as terminating at point (B) where hearer's upload (feedback) confirms the recovery of Speaker's intended meaning. Nevertheless, recursive (interactional) discourse is shown as extending to point (C) where feedback (upload) signals hearer's retrieval of speaker's unintended meaning, or where further elaboration is made on H's feedback thereby necessitating a recourse to the point of initiation (A) where speaker further elaborates $\mathrm{CG}$ in the uploading task which the hearer in turn downloads and uses inferentially for meaning; a process that may get repeated for a number of times thereby giving a cyclic modular to the schema.

Through inference, meaning is shown as derived through joint collaborative interaction of speaker and hearer. Meaning is thus a product of assumption of the "aboutness" or directedness of talk; Duranti [28], instead of being solely ipso facto or post facto. This is perceived as distinct from a situation featuring adjacent pairs alone which is mono- directional and relatively static. In other words, the encoding/decoding model's focus on adjacent pairs is individualistic instead of dyadic; communication is conceived as the transfer of information from one person to another (linear) and terminates with hearer's recognition of speaker's intention. In relating the operational schema to face management, it is believed that through participants' $\mathrm{CG}$ in aspects of belief, world knowledge, face, roles: PDR; task, goal) interlocutors make adjustments to the encoding and decoding of face-oriented locutions from point $\mathrm{X}$ (least polite/dispreferred) to point $\mathrm{Y}$ (most polite/preferred). Intended inferences from face-oriented locutions result on H's part on the basis of the extent of CG (belief, knowledge, etc.) shared with $\mathrm{S}$ (approximation to the $\mathrm{Y}$ axis) to arrive at point B. Hearer's feedback enables S's integration and subsequent confirmation of his initial (provisional interpreting) of face intent as being successful or otherwise. An unintended face related inferences is, on the other hand, localized to the left of the inference arrow, point $\mathrm{C}$ (approximation to $\mathrm{X}$ ) consequent upon inbalance in the level of $\mathrm{CG}$ between $\mathrm{S}$ and $\mathrm{H}$. H's feedback indicative of unintended face-related inference at point $\mathrm{C}$ then necessitates further enrichment of $\mathrm{CG}$ on the part of $\mathrm{S}$ which $\mathrm{H}$ collaboratively/ dynamically work out with him/her in recursive interactional discourse.

In discussing the relatedness of CG to the core pragmatic concepts of intention and implicature for the recovery of meaning here, it may be observed that the nature of communicative intention is at variance across pragmatic circles and among proponents of the Gricean Intention Theory, the Semantic Minimalists and the Social Interactional paradigm. While the Neo-Gricean school advocatesthe centrality of intention to success in communication, premised on audience design and speaker's apriori intention identification and derivation by inference, semantic minimalism hinges success in communication on propositional semantic contents and the socio-cultural, interactional paradigm envisions intention and meaning as a post factum construct, emergent and co-constructed in discourse.

It would appear that apologists of the divergent views have their good reasons both as mental postulates and operational modalities, as conversation interactions seem to demonstrate vagaries of interpretings with potential credence for the opposing stances. The present study wishes to accommodate the diversities as being a principle of "two sides of a coin" rather than that of polarity or parallelism with no hopes of convergence in view. This implies that interactional communication encompasses the a priori and post factum elements of intention as well as the conventional and nonce components of implicature; complexities which must of necessity be catered for by an objective approach in the analysis of the communicative process (Kecskes\&Mey [26])

Intention may be interpreted as both ipso facto and post facto in the sample data. The ipso facto or a priori dimension to intention entails working from something already known or self evident to arrive at a conclusion. Communicative 
intentions are believed to be made evident in our sample discourse and implicatures subsequently recovered because speaker and hearer employed definite words and expressions with determinate sense and reference for meaning encoding and decoding. The employment of ostensive stimulus in itself; Sperber \& Wilson [29], constitutes a display of communicative intention. In the words of Bilmes [20], speakers' intentions are displayed (in so far as they are displayed) because the utterance has meaning, hence negating the possibility of meaning being wholly based on speaker's displayed intention.

\section{Methodology}

The conceptual framework explicated above constitutes the analytical model applied to our sample datum; Health Awareness Programme on Walnut, as a sample of the four episodes studied by the researcher. The programme presenter is designated as $\mathrm{P}$, and the resource person as $\mathrm{C}$.

\section{Data Analysis}

Cappelon\&Lepore [30] identified semantic meaning as basic to pragmatic meaning. They assert that through the semantic propositional contents of utterances (consistent common core meaning) the relation of identity shared by speaker and hearer aid their mental assessment of the full propositional semantic contents of utterances utilized for the purpose of meaning derivation. Although the shared common core meaning of lexical items may be adduced as basic to the communicative process in this instance, the datum however indicates that semantic minimalism captured above does not suffice for the explanation of the encoding and decoding process of intention and meaning as it takes no account of nonlinguistic or contextual properties of interaction. The data indicates that linguistically encoded meaning fails to fully determine the intended proposition expressed as utterances' logical form always needs considerable contextual input to gain full propositional status. Speber\& Wilson [29].

Basically, therefore, meaning is primarily encoded and decoded by interlocutors through recourse to a common linguistic denominator comprising of phonological and syntactic structures and forms accessible to both parties. The use of simple, clear and often very familiar words in making unambiguous, concise statements help in the decoding and attachment of default implicature to almost all utterances in the data as a function of conventionality. This explains why meaning can be jointly attributed to words like 'walnut', 'cashew', 'banana', 'soursop', 'greet', 'God', etc. in the four episodes studied, or why certain expressions can be identified as greetings (welcome to ..., I salute our...), questions (na which one you bring...?, wetin walnut dey do ...?, what of the medicinal value...?, Wetin come be the thing weydey inside cashew ?), illustrations (for instance..., like all those people...) etc., with their attendant displayed intentions.

The context dependency of semantics (Carston, [31]) is inadvertently demonstrated in the simultaneous contextual development of semantic meaning in the context under study, a vital premise posited by Sperber and Wilson [29] for gaining full propositional status of utterances' logical forms. Instances of this in datum include:

\section{Sample 1}

Datum I

P: "Iyabiye, greet our people"

C: "I salute all our people of Edo State and environ and all over the places wey be say demdey hear us..."

Sample 2

$\mathrm{P}$ : Na which one you bring come, this one you think dey help person again?

C: Botanica name of ...en... Walnut na en we dey call Juglansregia.

The respondent (C) in sample 1 above demonstrates shared contextual-sensitivityof the semantic content of 'our people' with interlocutor, which on this occasion has been contextually enriched in accordance with the domain of discourse Carston[31]; a world knowledge semantic enrichment which far exceeds what is provided for by the semantic content of 'our people'. Sample 2 equally demonstrates a contextual enrichment of the semantic content of the question for the derivation of its full propositional content. This is evident in the fact that the response does not address the question's expressed propositional content (which could have been (1) I brought walnut, (2) yes, it helps people) or perceived speaker's intention, rather, answer in this instance is in response to what respondent adjudges or perceives to be the contextually relevant convention;Arundale[32]. The world knowledge and shared experience of interlocutors on the scene identifies a norm of interaction and interpretings in this context. The seemingly 'irrelevant' answer is in response to the established convention or often practiced norm of interaction in context. This underscores the fact that implicature is not necessarily always derived from speaker's perceived intention but often times a matter of conventionality.

As regards the common ground and face management interface in sample 1, the shared knowledge (CG) of participants about the situational context of the radio discourse recognizesritual politeness observance in matters of greetings, turn taking, conversational dominance and deference; culminating in stasis face management. In sample 2, S's upload negates and adjusts CG in context as a product of memory of all participants (retrodiction), glossed in face moves (interest in hearer and indirectness) to seek H's upload of CG on the subject matter. Hearer's feedback consequentlysupports/co-constructs face through appropriate next contribution to signal arrival at point $\mathrm{B}$ on schema, and adjusts CGto the $\mathrm{Y}$ axis by the provision of required information. Some other speech acts performed to signal attention, alignment with speaker, fill memory lapses, or confirm allusion, among others, derived from CG and remain inadvertently significant to face as face-work is intrinsic rather than exogenous to communication. It may be observed that normative and strategic politeness nuances are equally selected within the communal (socio-cultural) $\mathrm{CG}$ of 
participants reflected in ethical and linguistic politeness strategies of approbation, deictic distancing of self and other from disease conditions, etc. The relationship between face and CG here may then be considered as reciprocal; face management is a veritable $\mathrm{CG}$ tool, and $\mathrm{CG}$ conversely functions to achieve face management.

Sample 3

C: so, like this walnut now, e dey help to give us energy, if those people weydey eat am you see say demdey get enough energy.

P: so eget carbohydrate

$\mathrm{C}$ : E get carbohydrate very well

Intention is recovered in this instance not on the basis of identification of S's intention but by shared understanding (underpinned by mutual knowledge) of what can be legitimately implied in context. The linguistic context of 'walnut', 'eat', 'energy', 'vitamins', 'minerals'; coupled with the situational context of a health talk, triggers the conventional implicatures derived above. Implicature is interactionally achieved in each instance and intention is invoked as a post facto element through what Schegloff [33] tagged the discursive practice of "confirming allusions" (so e get carbohydrate?, So calcium dey walnut?, etc.). Through recursive discourse/meaning negotiation (point $\mathrm{C}$ on schema), implicature is co-jointly constructed and emergent through the dyadic nature of reasoning temporally extended forward in anticipation and backward in hind sight or retroactive assessment of what had already transpired, Arundale \& Good [34], Arundale [32]; which justifies each implicature above on the basis of the preceeding utterance and what such transpires into in this context (accountability and aboutness), and not an inherent intention on the part of speaker. Iyabiye's intention may have simply been to locate the functional benefits of each fruit and not the nutritional components but in the words of Duranti[35] participants in actual interaction cannot always know what their actions or words are meant to achieve.

The projective consequence of interpretings in some of the instances above is evident in the detour of discourse pattern (at the point of implicature) in the direction of categories of food classes (e get carbohydrate very well and a lot of vitamins like vitamin A dey..., vitamin B..., etc) instead of the previous line of functional benefits towed by speaker as in datum I.

\section{Sample 4}

C: Like in the morning like this you go feel weak, so tired, you go see say when we combine walnut with other medical value - walnut na cook na en demdey cook am because it's not good to eat am raw.

It may be observed in sample 4 above that the mechanism of interpretation consists of conventionality as much as intentionality; Duranti [35]. The input for the conventional meaning mechanism is in this instance truncated by the flouting of the quantity maxim. The utterance above is fragmented and incomplete in propositional contents thereby blocking a conventional meaning. Through intentionality as a property of human consciousness of being directed toward or being about something - "aboutness";Duranti[28], hearer may establish implicature as a link between the preceding symptomatic conditions and the combination of walnut with 'other medicinal value' but not possibly through the recognition of speaker's intention.

Implicature on the other hand is generated contextually by flouting the maxims above through recourse to expectations about what can or what cannot be implied in this context;Haugh [36]. Participants' mutual knowledge of the world and the generic constraints of the health talk context presuppose a professional ethical convention of information management on the part of the resource person, which finds expression in this context by the intentional conservation/reservation of core, vital or intimate information for professional reasons (adjustment of $\mathrm{CG}$ towards the $\mathrm{X}$ axis). An example is:

Datum I: 5(ii) c: "other medicinal value" (avoidance)

From the analysis above, it is quite evident that both the encoded and constructed sides of intention may co-exist in conversational interaction. While encoded intention may be conceived as a priori in certain instances, and accessible through default implicature by means of normative accountability (logicality), intention may equally be a post factum element co-jointly constructed with implicature resulting from aboutness of talk.

Implicature on most occasions is derived in the data as a result of invoking norms that are reflexively constitutive of the activity in which participants are engaged (e.gimplicature in datum I: 1(i), and the unfolding circumstance to which it is applied (e.g the ensuing discourse from C's response to item 13 in the text to P's back channel 'okay' after item 18 in datum (see appendix I).

The norm of interaction in discourse (radio broadcast) observes patterns of turn taking underpinned by roles played by participants on the scene. This includes patterns of overlap, truncation, gaps, etc., exhibited in context. The same underlying factor extends to participants and their manner of address, deference, etc. Culturally motivated aspects of politeness may be observed in the use of person deictics where the personal pronouns 'you' is intentionally avoided in direct reference to audience, especially in connection with negative connotative content.

Overall, the activity (talk) type in this instance hold implications for the notion of intention both as a priori and post factum element. Structurally divisible into three composite parts: Beginning, middle, end or introduction, body, conclusion; the text represents intention at the outset as explicit and displayed as information regarding the what and whereofs of the programme are provided. The middle (body) of text is characteristic of intention as a co-constructed and dynamic construct where participants mutually contribute to the encoding and decoding of intention and the attendant implicature either through default or nonce implicature.

The conclusion on the other hand captures intention as a post factum, an emergent construct which culminates discourse in the location and identification of places and persons to whom the listening audience is directed for assistance in the attainment of the ultimate aim of the health 
talk programme.

The above indicates that the nature of intention is influenced by the talk (activity) type. Speech types such as directives (questions, order, request) may most often represent intention as ipso facto because they do not entertain an interactive avenue where intention may be co-jointly constructed or implicature co-jointly derived. Activity types informed by communication goals such as passing a resolution, reaching a consensus, striking a bargain, etc., may most often represent intention as emergent and post facto.

\section{Findings}

The analysis established common ground as dynamic, adjustable and co- constructed in discourse. Face-work and CG are also interdependent in context as the selection and success of face management strategies derive from the $\mathrm{CG}$ of participants, and their $\mathrm{CG}$ equips them for the identification and interpretation of politeness strategies for the recovery of communicative intention and inference in discourse. In respect to evidence(s) from data which demonstrate communicative intention as ipso facto or post facto, the analyses indicate that communicative intention may be perceived as both a priori and post facto in data, while intention is recovered via implicature as products of intentionality and conventionality. It may be observed from the analysis that intentions are mostly displayed or made explicit e.g.

"Wetin walnut dey do for body?",

"So what of the medicine, the medicinal value?"

"Iyabiyewetin e dey do for bodi?

Conversely, communicative intention are post facto (cojointly constructed) in cases of accountability which is either normative (aboutness of talk) or moral (social actors giving reasons, motives or causes of their actions). Normative accountability in terms of generic presumptions of aboutness of talk is derived by interlocutors in data based on a dyadic cognizing (retroactive and anticipatory) assessment of locution in context. Supporting evidences from data include:

1) (a) "E dey help to give us energy... people weydey eat am... dey get energy"

(b) "So e get carbohydrate"

2) (a) "We never talk about walnut before, na which one you bring come, this one dey help person again?"

(b) "Botanical name of en... walnut na en we dey call JuglansRegia

Excerpts 1 and 2 feature adjacent pairs where normative accountability (default meaning) arises from generic presumption of about ness of talk i.e interpretings made in response to preceding contribution to discourse.

It may be safely inferred from numbers 1-2 above that implicature is not derived from inferences about speaker's intentions but through projective and retroactive inferencing. The representation of the a priori and the post facto dimensions in the data further underscores the imperativeness of accommodating both dimensions of intention/implicaturein the analysis of any comprehensive account of meaning.

\section{Conclusion}

A reassessment of the contribution of the trio of intention, common ground and implicature to the success of meaning negotiation reveals that the derivation of implicature (intended/unintended) is a matter of both intentionality and conventionality, and common ground is identified as dynamic and relative to the communication endeavour rather than static. Contextual factors (situational, participants, topic, activity type and goal) are constantly assessed by interactants in adjudging the extent and form of common ground they subscribe to in interaction. It is may be inferred that this conception of common ground as an adjustable construct that is coconstructed in interaction provides insight into its significance for communicative intention (meaning) negotiation and face negotiation in the context of the pidgin radio discourse.

\section{Appendix}

\section{Appendix I}

\section{HEALTH AWARENESS PROGRAMME IN PIDGIN}

Datum 1: Walnut

$\mathrm{P}:{ }^{1}$ Welcome to ${ }^{2(\mathrm{i}, \mathrm{iii})}$ our popular herbal programme, the world of herbs with Iyabiye and today, ${ }^{3} \mathrm{I}$ get the chief for studio, Iyabiyedey with us, Iyabiye, greet our people

C: ${ }^{4}$ I salute ${ }^{5}$ all our people of Edo State and environs and all the places wey be say dem be hear us. ${ }^{6}$ The ear wey you dey take hear us, God no go let the ear get problem o because I believe say ${ }^{7}$ information na power. So, ${ }^{8}$ once you dey tune in to EBS, you go dey listen to good, good information. ${ }^{9}$ Make you no miss this programme o.

P:Iyabiye, ${ }^{10} \mathrm{I}$ think say you bring walnut come studio today. En hen, you ${ }^{11}$ know say we never talk about walnut before. ${ }^{12} \mathrm{Na}$ which one you bring come, ${ }^{13}$ this one you think dey help person again?

$\mathrm{C}$ :Botanica name of en. walnutna en we dey call Juglansregia

P: ${ }^{14}$ Juglansregia

$\mathrm{C}: \mathrm{Na}$ enbe botanica name of wal nut and thefamily name na en

$\mathrm{P}:{ }^{15}$ Okay

C:we dey call Juglansdasie, Juglansdasiena en be the family name of walnut

P:Okay

C:If you see ${ }^{16}$ many people dey eat walnut but, you no go, people no dey know the medicinal aspect of it. They don't know the medicinal em...em importance of this walnut, but they will just carry walnut begin dey eat am. You see, God is so powerful and God created all these herbs for our own sake. Many people dey eat walnut, especially all those children, dem go say, tchi, make they just eat am, but they no go know say e dey cure some certain things inside their body system, that is why I dey always dey talk say there is power in herbs. If you go inside Quran God talk of herbs, if you go inside Bible, God talk of herbs so, ${ }^{17}$ no way wey be say you go fit abstain yourself from herbs because our body chemistry is natural, because na God design am, no chemical no artificial. Nothing 
wey be say e dey diluted to our body chemistry

$\mathrm{P}:{ }^{24}$ Wetin walnutdey do for body?

$\mathrm{C}$ :So, like this walnut now, e dey help to give us energy. If those people weydey eat am you see say demdey get enough energy

P:So eget Carbohydrate

$\mathrm{C}:{ }^{18(\mathrm{i})} \mathrm{E}$ get carbohydrate very well

P:Okay

$\mathrm{C}$ :And a lot of vitamins. Like vitamin A dey there wey be retinol, vitamin B dey there which is thiamine. So, all these vitamin deyplentiweydey inside walnut. Like B1 too e dey there, B2 dey there, B6, all these are vitamins wey be say e dey inside walnut ${ }^{19}$ and we know, all of us know the function of vitamins; vitamins-rich food, vitamins dey assist the body function very well. So like minerals too, e dey get a lot of mineral like calcium dey e...e..walnut, like phosphorus dey walnut, like magnesium dey walnut, like iron too, wey our body need, wey our bone need, e dey walnut. Soonce

$\mathrm{P}:{ }^{25}$ Thesena the food value

$\mathrm{C}$ :In fact those are the chemistry aspect ofwalnut

$\mathrm{P}:{ }^{26}$ So what of the medicine, the medicinal value

$\mathrm{C}$ :The medicinal aspect of walnut be say, one, for instance ${ }^{20}$ all those people wey be say they say dem be weak, weydemdey weak all the time weydem no dey get strength. Like when you walk from one pole to another you go become tired you become malaise you go dey experience severe waist pain, general weakness of the body, like in the morning like this, you go feel weak, so tired, you go see say when we combine walnut with other medicinal value - walnut na cook na en demdey cook am because it's not good to eat am raw. If you eat am raw like that without cooking you no go enjoy the flavour because the taste, e no go even sweet you to eat am but when you cook am, you go see say you go fit enjoy am because e dey very palatable and when you dey eat walnut, you go see say a lot of e...e.. water go dey come out of there. Like those people wey be say demdey experience severe general weakness of the body, chest pain, bone go dey pain them, for them to waka from one pole na another, na problem for them

$\mathrm{P}$ :Socalcium dey walnut

$\mathrm{C}:{ }^{18(i i)}$ Calcium, in fact, e dey walnut

P:Okay
$\mathrm{C}:{ }^{21} \mathrm{E}$ go dey assist you, ${ }^{27}$ your body go dey function, the way esuppose todey function. So once you experience any discomfort inside your body system, ${ }^{22}$ may be you dey experience general weakness, headache all the time, em.. waist pain, chest pain, all these things is as a function of wal nut wey be say e fit assist you. ${ }^{28}$ So for further information and advice, you fit reach us for no $1 \mathrm{~B}, 4^{\text {th }}$ welain, for back of NTA for T.V road for Benin City here for Edo state, 73 Akintolaroad by new road, Sapele, Benin- Asabaexpresss way, by Urobi junction inside that new Lagos motor park for Agbor. And you weydey Onitsha, we dey for number 53, by savoy junction, Okar road for Onitsha. And you weydeyAuchi, we dey for number 6, Obudu road, Sabo road before Golden palace hotel for Auchi. And you weydey for Sabongida Aura, we dey for number 35, commercial lane for Sabongida Aura. My GSM number naem be 08034102250 . ${ }^{23(i)}$ So make una remain blessed and make una eat beta food.

$\mathrm{P}:{ }^{2(i i)} \mathrm{My}$ people, that naunaprogramme today o, make una stay well.

\section{Appendix II}

TRANSCRIPTION CONVENTION.

The following represent the convention adopted in the transcription of the radio discourse.

P:presenter

$\mathrm{C}$ :Resource person (commentator)

Overlapping utterances

$<$ Explanation of paralinguistic convention/ nonverbal cue

\section{Appendix III}

\section{English Language Glosses of Some Pidgin Expressions.} Introduction

The information provided below represents a simple English translation of some core pidgin expressions in the corpus analyzed. The entire text is not translated into English word for word considering the implication of such for the present volume. Consequently, words lexpressions considered as portending semantic impediment do non-pidgin speakers are extracted and provided with their English Language equivalents.

Table 1. English Glossary of Nigerian Pidgin Words/Expressions.

\begin{tabular}{|c|c|c|c|}
\hline $\mathbf{S} / \mathbf{N}$ & Pidgin Word /Expression & English Equivalent & Example \\
\hline 1 & $\mathrm{~A} / \mathrm{I}$ & I & $\begin{array}{l}\text { A know say }=\mathrm{I} \text { know that } \\
\text { E dey good }=\text { it is good }\end{array}$ \\
\hline 2 & $\mathrm{E}$ & It, (subjective case), it is, $\mathrm{He}$ & $\begin{array}{l}\text { E good for the body }=\text { It is good for the body } \\
\text { If e dey among people }=\text { if heis in the midst of people }\end{array}$ \\
\hline 3 & Get & Have, Has & $\begin{array}{l}\text { I get the chief }=\text { I have the chief } \\
\text { E get carbohydrate }=\text { it has (contains) carbohydrate }\end{array}$ \\
\hline 4 & $\begin{array}{l}\text { For } \\
\text { For }\end{array}$ & $\begin{array}{l}\text { In/At } \\
\text { From }\end{array}$ & $\begin{array}{l}\text { For studio }=\text { in (the) studio } \\
\text { Na sickness go run for us }=\text { It is sickness that will run from us }\end{array}$ \\
\hline 5 & Wey & That & The ear wey you... = the ear that you... \\
\hline 6 & Dey & $\begin{array}{l}\text { Forms of 'be': am, is, are forms of } \\
\text { 'do' } \\
\text { To }\end{array}$ & $\begin{array}{l}\text { You dey = you are } \\
\text { wey e dey your body = that is in your body Thiamine dey there }=\text { thiamine is } \\
\text { thereyou dey get pain = you do have pains } \\
\text { we dey use am dey cure = we do use it to cure }\end{array}$ \\
\hline 7 & $\begin{array}{l}\text { Go } \\
\text { Go dey }\end{array}$ & $\begin{array}{l}\text { Will /shall Auxillary verb } \\
\text { Will be }\end{array}$ & $\begin{array}{l}\text { Dem go tell you }=\text { they will tell you } \ldots \\
\text { Dem go dey say }=\text { they will be saying }\end{array}$ \\
\hline
\end{tabular}




\begin{tabular}{|c|c|c|c|}
\hline $\mathbf{S} / \mathbf{N}$ & Pidgin Word/Expression & English Equivalent & Example \\
\hline 8 & $\begin{array}{l}\text { No } \\
\text { E no }\end{array}$ & $\begin{array}{l}\text { Not (negator) } \\
\text { It is not }\end{array}$ & God no go $=$ God will not... \\
\hline 9 & No dey & $\begin{array}{l}\text { Negator }+ \text { do (do not), subsuming the } \\
\text { auxiliary and usually preceded by a } \\
\text { noun or pronoun subject }\end{array}$ & $\begin{array}{l}\text { You no dey give am }=\text { You do not give it } \\
\text { Enodey coincide }=\text { It does not coincide }\end{array}$ \\
\hline 10 & $\begin{array}{l}\mathrm{Na} \\
\mathrm{Na}\end{array}$ & $\begin{array}{l}\text { That is } \\
\text { It is }\end{array}$ & Na unaprogramme today $\mathrm{o}=$ That is your programme today \\
\hline 11 & Una & $\begin{array}{l}\text { You (plural) } \\
\text { Your }\end{array}$ & $\begin{array}{l}\text { Make una no miss this programme } o=\text { Don't }(\text { you }) \text { miss this programme } \\
\text { This naunaprogramme }=\text { This is your programme }\end{array}$ \\
\hline 12 & Say & That & $\begin{array}{l}\text { I think say }=\text { I thought that } \\
\text { You know say= you know that }\end{array}$ \\
\hline 13 & Am, En & It (objective case) & $\begin{array}{l}\text { Eat am = Eat it } \\
\text { Na en be the thing = That is (it) the thing }\end{array}$ \\
\hline 14 & Chuku-chuku & Spikes & E get chuku-chuku for the body $=$ It is spiky \\
\hline 15 & Dem & They & If demdey congregation now $=$ If they are in a congregation \\
\hline 16 & Waka & Walk & If demwaka from one pole to another $=$ if they walk from one pole to another \\
\hline 17 & $\mathrm{~A}, \mathrm{I}$ & I & A (I) know say e won discuss banana $=\mathrm{I}$ know that he wants to discuss banana \\
\hline 18 & For & Would have & a (I) for say = I would have thought (said) that \\
\hline 19 & Wan & Want/want to & If dem wan piss $=$ If they want to urinate \\
\hline 20 & Fit & Can & A (I) fit talk say $=\mathrm{I}$ can say that \\
\hline
\end{tabular}

\section{References}

[1] Adegbija, E. E. (1989). A comparative study of politeness phenomenon in English Language in Nigeria. ITL Review of Applied Linguistic Vol. 76, 43-62.

[2] Friedrich, U. \& Hans-jorg S. (2013). An Introduction to Cognitive Linguistics. $2^{\text {nd }}$ Ed. London: Routledge.

[3] Rundquist, S. (1992). In directness: A gender study of flouting Grice's maxims. Journal of pragmatics. 18(5) 431-49

[4] Thomas, J. (1995). Meaning in interaction: An introduction to Pragmatics. England: Longman.

[5] Brown, P. \& Levinson, S. C. (1987). Politeness: Some Universals in language Usage. Cambridge: University Press.

[6] Arundale, R. B. (1999). An alternative model and Ideology of Communication for an alternative to politeness theory. Pragmatics9:119-153. International Pragmatics Association.

[7] Davis, W.(2007). How normative is implicature. Journal of Pragmatics. 39:1655-1672.

[8] Arundale R. B. (2005). Pragmatics, conversational implicative, and conversation in K. Fitch and R. Sanders (Eds) Handbook of Language and Social Interaction. Mahwah, N. J.

[9] Leech, G.\& Short, M. H. (1981). Style in fiction. London and New York: Longman.

[10] Austin, J. L. (1962). How to do things with words. Oxford: Oxford University Press.

[11] Cooper, D. E.(1973). Philosophy and the nature of language. London: Longman.

[12] Grice, H. P. (1975). Logic and Conversation. In Cole and Morgan (Eds), Syntax and Semantics, Vol. 3 Speect acts, New York: Academic Press.

[13] Bach, K. \&Harnish, R. M. (1979). Linguistic communication and speech acts. Massachusetts and London: MIT Press Cambridge.

14] Babatunde, S. T. (1997). Axes to the roots: A lexico-semantic analysis of TundeOlusunle's Fingermarks. In R. A. Lawal (Ed) Stylitics in theory and practice. Ilorin: Paragon Books.

[15] Brown, P. \& Levinson, S. C. (1978). Universals in language usage: Politeness phenomena. In Goody, E. N. Questions and Politeness. Cambridge: Cambridge University Press.

[16] Arundale R. B. (2006) Face as relational and interactional: acommunication framework for research on face, facework and politeness. Journal of Politeness Research 2:193-216.

[17] Haugh M. C. (2014). Intention in pragmatics. Introduction to special issue of intercultural pragmatics.

[18] Arundale R. B. (2017) Individually and socially-based understandings in researching professional discourse. Journal of Modern Languages [S.I.], V. 23, n.1, p.n.1, p.1-12.

[19] Assimakopoulo, S. (2008). Intention, common ground and the availability of semantic Content: A relevance theoretical approach. In I. Kecskes and J. Mey (Eds) intention, common ground and Egocentric Speaker-hearer (pp. 105-126). New York: Mouton de Gruyter

[20] Bilmes, J. (1986). Discourse and behaviour. New York: Plenum Press.

[21] Clark, H. H. (1996). Using Language. Cambridge: Cambridge University Press.

[22] Bar, P. \& B. Keysan (2005). Making sense of how we make sense. The Paradox of egocentrism in Language use. In $\mathrm{H}$. Colston and A. Katz (Eds) Figurative language comprehension: Social and cultural influences.21-41 Hilsdale, NJ: Eribaum.

[23] Colston, H. L. (2005). On Sociocultural and nonliteral: A synopsis and a prophesy. In H. L. Colson and A. Katz (Eds) Figurative Language comprehension. 1-20 Hillsdale, N. J.: Erlbaum.

[24] Fodor, J. A. (1998). Concepts. Where cognitive science went wrong. New York: oxford University Press.

[25] Colston, H. L. (2008). A new look at common ground: memory, egocentrism and joint meaning in I, Kecskes and J. Mey (Eds)Intention, common ground and the egocentric speaker-hearer. (151-188) New York:Mouton de Gruyter. 
[26] Kecskes, I, \&Mey J. (2008)Introduction. In I kecskes and J Mey (Eds)Intention, common ground and the egocentric speaker-hearer (pp. 1-3). New York: Moutonde Gruyter.

[27] Babawarun, T. C. (2014). Face management and Intention in Nigerian pidgin radio discourse (Unpublished doctoral dissertation). University of Ilorin, Ilorin.

[28] Duranti, A. (2006). The social onthology of intentions. Discourse Studies. 8:31-40

[29] Sperber, D.\& Wilson D. (2005). Pragmatics. In F Jackson and M Smith (Eds) The Oxford Handbook of Contemporary Philosophy. Oxford university Press.

[30] Cappelen, H \&Lepore, E. (2005)Insensitive semantics. A defense of semantic minimalism and speech act. Pluralism. Malden: Black Well.

[31] Carston, R. (2002) Thoughts and utterances. Oxford: Blackwell.
[32] Arundale R. B (2012) On understandings of communication: A response to Wedgewood. Intercultural pragmatics. 9,137159.

[33] Schegloff, E (1996). Confirming allusions: Towards an empirical account of account of action. American Journal of Sociology 102:161-216.

[34] Arundale R. B.\& Good D (2002). Boundaries and sequences in studying conversation. In A. Fetzer \& C Merekord (Elds) rethinking sequentiality. Linguisticsmeets conversationalInteraction. Amsterdan: John Benjamins 121150 .

[35] Duranti, A. (2000). Intentionality. In Journal of Linguistic Anthropology 9 (1-2): 134-136. American Anthropological Association.

[36] Haugh, M. C. (2008). The place of intention in the interactional achievement of implicature in I. Kecskes and J. Mey (Eds) Intention, common ground and the egocentric speaker-hearer(pp. 45-86) New York: Mouton de Gruyter. 